\title{
Do air pollutants as well as meteorological factors impact Corona Virus Disease 2019 (COVID-19)? Evidence from China based on the geographical perspective
}

\author{
Lin $\mathrm{Pei}^{1} \cdot$ Xiaoxia Wang ${ }^{2} \cdot$ Bin Guo $^{2}$ (D) Hongjun Guo ${ }^{3} \cdot \mathrm{Yan}_{\mathrm{Yu}}{ }^{1}$ \\ Received: 20 December 2020 / Accepted: 8 February 2021 / Published online: 5 March 2021 \\ (C) The Author(s), under exclusive licence to Springer-Verlag GmbH, DE part of Springer Nature 2021
}

\begin{abstract}
The COVID-19 is still a huge challenge that seriously threatens public health globally. Previous studies focused on the influence of air pollutants and probable meteorological parameters on confirmed COVID-19 infections via epidemiological methods, whereas the findings of relations between possible variables and COVID-19 incidences using geographical perspective were scarce. In the present study, data concerning confirmed COVID-19 cases and possible affecting factors were collected for 325 cities across China up to May 27, 2020. The geographically weighted regression (GWR) model was introduced to explore the impact of probable determinants on confirmed COVID-19 incidences. Some results were obtained. AQI, $\mathrm{PM}_{2.5}$, and $\mathrm{PM}_{10}$ demonstrated significantly positive impacts on COVID-19 during the most study period with the majority lag group $(P<0.05)$. Nevertheless, the relation of temperature with COVID-19 was significantly negative $(P<0.05)$. Especially, CO exhibited a negative effect on COVID-19 in most study period with the majority lag group. The impacts of each possible determinant on COVID-19 represented significantly spatial heterogeneity. The obvious influence of the majority of possible factors on COVID-19 was mainly detected during the after lockdown period with the lag 21 group. Although the COVID-19 spreading has been effectively controlled by tough measures taken by the Chinese government, the study findings remind us to address the air pollution issues persistently for protecting human health.
\end{abstract}

Keywords COVID-19 $\cdot$ Air pollutants $\cdot$ Meteorological factors $\cdot$ GWR $\cdot$ GIS

\section{Introduction}

Twenty-seven illnesses with pneumonia infection of unknown etiology were reported in December 2019 in Wuhan, Hubei

Lin Pei, Xiaoxia Wang, Bin Guo and Hongjun Guo contributed equally to this work.

Responsible Editor: Lotfi Aleya

Bin Guo

guobin12@xust.edu.cn

Hongjun Guo

2272859673@qq.com

$\triangle$ Yan $\mathrm{Yu}$

yuyan@mail.xjtu.edu.cn

1 School of Public Health, Xi'an Jiaotong University, Xi'an, Shaanxi, China

2 College of Geomatics, Xi'an University of Science and Technology, Xi'an, Shaanxi, China

3 Weinan Central Hospital, Weinan, Shaanxi, China
Province, China (Huang et al. 2020). Subsequently, a novel coronavirus termed SARS-CoV-2 was confirmed as the causative pathogen of COVID-19 on 7 January ( $\mathrm{Lu}$ et al. 2020; $\mathrm{Li}$ et al. 2020a). Then, the World Health Organization (WHO) declared the COVID-19 pandemic a public health emergency of international concern on 30 January 2020 (WHO 2020a; Sohrabi et al. 2020). Later, as of February 15, 2020, 68,500 cumulative identified cases and 1665 deaths have been documented domestically (NHC 2020), and 528 cases and 2 deaths were reported out of China (WHO 2020b). What's more, many countries including the USA, Spain, Italy, Germany, the UK, France, and China were affected by COVID-2019 spreading rapidly worldwide. More than 18.96 million cases of COVID-2019 had been diagnosed and confirmed in about 200 countries and territories until August 6, 2020. Fortunately, the COVID-19 pandemic has been effectively restrained in China for a series of measures that have been implemented including traffic restrictions, lockdown, asking residents to stay at home, and to begin social distancing, closing many industries. Unfortunately, the COVID-19 is still spreading all over the world and there are no signals of disappearance. 
So, it is urgent to further research the possible influence factors of COVID-19 and take measures to control the spread of the virus.

Previous studies proved that the SARS-CoV-2, SARS$\mathrm{CoV}$, and middle east respiratory syndrome coronavirus (MERS-CoV) belonged to the same virus family. Furthermore, three of these coronaviruses have been confirmed to be able to transmit through the air (Zhou et al. 2020; Yu et al. 2004; Zumla and Hui 2014; Guo et al. 2020). Moreover, the relationship between SARS and MERS with air quality and meteorological conditions has been identified (Cui et al. 2003; Lin et al. 2006; Gardner et al. 2019). Meanwhile, some specific relations of the virus with air quality and environmental factors have been proved in published researches (Zhu et al. 2020; Xu et al. 2020a). For example, particulate matter (PM) with an aerodynamic diameter smaller than $10 \mu \mathrm{m}\left(\mathrm{PM}_{10}\right)$ has positive effects on SARS mortality. Also, the spread of many viral diseases including influenza and the respiratory syncytial virus has been confirmed to be affected by meteorological conditions, such as temperature and humidity (Bloom-Feshbach et al. 2013; Lowen et al. 2007). The epidemiological investigation demonstrated that the risk of transmission of SARS and MERS may be raised in the condition of lower temperature (Lin et al. 2006; Gardner et al. 2019), and infection with MERS-CoV is more likely to appear under dry conditions (Gardner et al. 2019). So, it is reasonable to infer that air quality and meteorological conditions may influence the spread of COVID-19.

Some related qualitative analyses of the relations between COVID-19 and air pollutants have been reported recently. For example, Lombardy and Northern Italian regions of the Po Valley (Padana Plain), an area identified as one of the most polluted regions with high concentrations of particulate matter (PM) in Europe, have undergone the rapid spreading of COVID-19 (ISS 2020; Fattorini and Regoli 2020). A hypothesis concerning a possible link between the high mortality of COVID-19 and the PM concentrations in Northern Italy has been released on March 16 by the Italian Society of Environmental Medicine (SIMA) (SIMA 2020; Setti et al. 2020). Besides, a significant relationship has been detected between the geographical distribution of the 110 Italian Provinces with exceeding daily $\mathrm{PM}_{10}$ concentrations and the spreading of the COVID-19 infection (ISS 2020). Furthermore, some quantitative researches on the relationship between the COVID-19 infection and environmental factors have been conducted in the U.S. and China after the COVID-19 pandemic outbreak. For example, in China, Zhu et al. 2020 utilized the Generalized Additive Model (GAM) to explore the relations between the concentrations of air pollutants and daily COVID-19 confirmed incidences and found that particles with diameters $\leq$ $2.5 \mu \mathrm{m}\left(\mathrm{PM}_{2.5}\right)$, particles with diameters $\leq 10 \mu \mathrm{m}\left(\mathrm{PM}_{10}\right)$, carbon monoxide $(\mathrm{CO})$, nitrogen dioxide $\left(\mathrm{NO}_{2}\right)$, and ozone
$\left(\mathrm{O}_{3}\right)$ have positive effects on the number of COVID-19 incidences. However, $\mathrm{SO}_{2}$ posed an adverse effect on the COVID-19 confirmed incidences. Meanwhile, a Poisson regression model was performed to identify the association between air quality index (AQI) and COVID-19 confirmed incidences. The results showed that the effect of AQI on confirmed incidences was statistically significant in several cities of China (Xu et al. 2020a). Moreover, in the USA, the zero-inflated negative binomial mixed models have been conducted to conclude the effects of long-term $\mathrm{PM}_{2.5}$ exposure on COVID-19 deaths by the faculties from Harvard University. They confirmed that an increase of only 1 $\mu \mathrm{g} / \mathrm{m}^{3}$ in $\mathrm{PM}_{2.5}$ concentration was associated with a $15 \%$ rise in the COVID-19 death rate and $95 \%$ confidence interval $(\mathrm{CI})(5 \%, 25 \%)$ (Wu et al. 2020a). So, it is reasonable to speculate that the possible additional factor for anomalous COVID-19 outbreaks is high PM concentration based on the available literature. Though the association between COVID-19 confirmed incidences and air pollutants has been explored at a global scale from an epidemiology and biostatistics perspective, the COVID19 maybe not only affected by air pollutants but also by meteorological conditions and other possible factors such as dietary habit, customs, and etiquette. Furthermore, the distribution of COVID-19 exhibited spatial heterogeneity in Italy, China, and the USA, and air pollution and environmental factors also demonstrate different distribution characteristics. So, the traditional epidemiological models were the global model that can hardly be used to detect the relation between pandemic and affecting factors locally. Alternatively, the Geographical Weighted Regression Model (GWR) which is a local model supplies a new perspective for exploring the relation between COVID19 and air pollution locally. So do the environmental and meteorological factors affect the COVID-19 confirmed incidences locally? Do the number of COVID-19 confirmed incidences change in line with the environmental and meteorological factors? Understanding the causes of COVID-19 from an interdisciplinary view is still a big challenge. This study attempts to estimate the influence of possible environmental and meteorological factors on COVID-19 confirmed incidences under the geographical perspective. The present study aims (1) to analyze the relations between confirmed COVID-19 incidences and the possible environmental and meteorological determinants using the Geographically Weighted Regression model (GWR) during three periods of COVID-19 outbreak at four lag group across China, (2) to evaluate the impact of each potential variable on confirmed COVID-19 incidences, and (3) to map the coefficient of influence factor obtained from the GWR model for demonstrating the spatial heterogeneity of effects on confirmed COVID19 incidences for each potential factor. 


\section{Method and material}

\section{Study area}

The current study selected 325 cities containing at least one COVID-19 confirmed case up to May 27, 2020, in China as a study area (Fig. 1). May 27 was used as the deadline for the study because this study was launched at the beginning of June 2020 and the dataset for COVID-19 confirmed case was updated up to May 27, 2020, at that moment. These cities are mainly distributed in the east and southeast parts of the mainland of China. Eighty-two thousand nine hundred ninetythree COVID-19 confirmed cases have been identified in entire China as of May 27, 2020, according to the National Health Commission.

\section{Data source and preprocessing}

Daily COVID-19 confirmed cases from Dec 31, 2019, to May 27, 2020, for each city were released from local health commissions on the official websites. All COVID-19 confirmed cases data used in the current study were allowed by patients for only academic studying, and all patients' privacy concerning name and ID identification card numbers were excluded before the dataset release. This study covered three periods including from the start point of the COVID-19 outbreak to lockdown (from Dec 23, 2019, to Jan 23, 2020), from lockdown to reopening (from January 23, 2020, to April 8, 2020), and after reopening (from April 8, 2020, to May 27, 2020), respectively. We selected before lockdown (BL) as one of the study periods because no protection measures have been taken by a human and people can go outside without wearing a mask during this period. We can exclude the effects of measures on COVID-19 confirmed incidences and speculate one of the additional reasons for COVID-19 incidence was potential environmental and meteorological factors. Meanwhile, the duration of lockdown (L) was chosen as the study period for we attempted to detect the influence degree of measures taken by the government on the number of COVID19 confirmed incidences, and people hardly can go outside except for basic living needs and was asked to wear a mask during this period. Furthermore, after lockdown (AL) was chosen as a study period for we can identify if the number of COVID-19 confirmed incidences was affected by not only measures but also possible factors, people can go outside smoothly with the negative COVID-19 code and was encouraged to wear a mask during this period.

Air pollutants data including air quality index (AQI), particles with diameters $\leq 2.5 \mu \mathrm{m}\left(\mathrm{PM}_{2.5}\right)$, particles with diameters $\leq 10 \mu \mathrm{m}\left(\mathrm{PM}_{10}\right)$, sulfur dioxide $\left(\mathrm{SO}_{2}\right)$, carbon monoxide $(\mathrm{CO})$, nitrogen dioxide $\left(\mathrm{NO}_{2}\right)$, and ozone $\left(\mathrm{O}_{3}\right)$ were made available from the China National Environmental

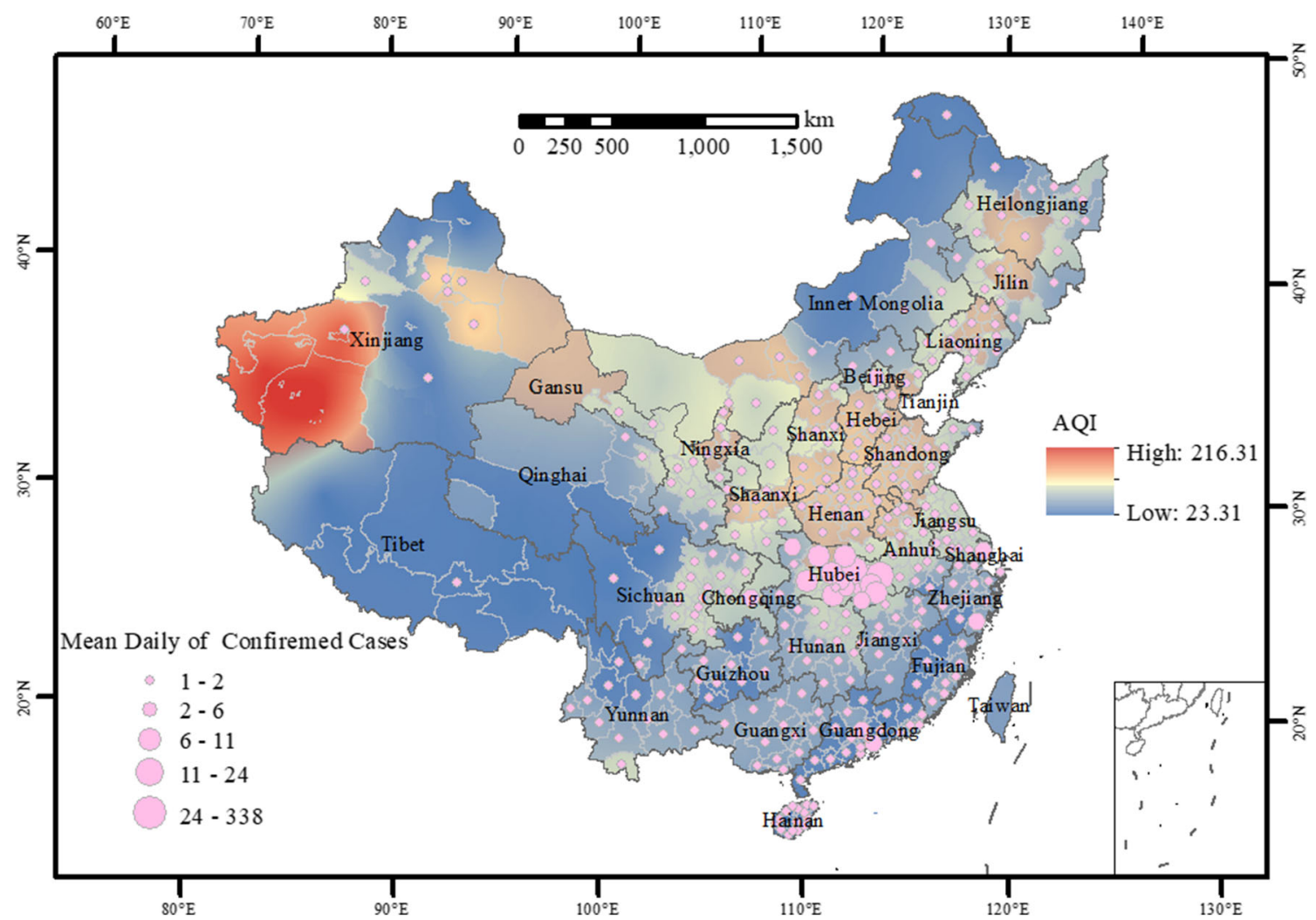

Fig. 1. The spatial distribution map of mean daily COVID-19 confirmed incidences and AQI in the mainland of China from Dec 31, 2019, to May 27, 2020 
Monitoring Centre (CNEMC) (http://www.cnemc.cn). Meteorological data on daily mean temperature (TEM), relative humidity $(\mathrm{RH})$, precipitation (PRE), and wind speed (WS) during the study period were made available from the National Meteorological Information Center (http://data.cma. cn).

Previous researches confirmed that the effect of air pollution can last for several days (Lin et al. 2018; Myung et al. 2019; Xie et al. 2019; Yang et al. 2020). Furthermore, an incubation period of 1-14 days for COVID-19 was reported by the National Health Commission in China. So, the current study determined to use a moving-average method to capture the cumulative lag effect of ambient air pollution (Duan et al. 2019; Li et al. 2018; Yang et al. 2020). Meanwhile, daily COVID-19 confirmed incidence was chosen to exclude the influence of the population density for COVID-19 confirmed cases. Thus, in this study, the relation between moving average concentration of air pollutants (lag0-7, lag0-14, lag0-21) and daily COVID-19 confirmed incidence (Hastie 2017; Liu et al. 2020; Adhikari and Yin 2020) were estimated through the GWR model.

\section{GWR model}

A GWR model (Fotheringham et al. 2002; Guo et al. 2021a; Guo et al. 2021b) was developed based on Equation (1) in the present study.

COVID_19 daily confirmed incidences ${ }_{i}$

$$
=\beta_{0}\left(\mu_{i}, v_{i}\right)+\beta_{1}\left(\mu_{i}, v_{i}\right) * X_{i}+\varepsilon_{i}
$$

where COVID_19 daily confirmed incidences ${ }_{i}$ is the COVID-19 confirmed incidences of the city $i$ at location $\left(\mu_{\mathrm{i}}\right.$, $\left.v_{\mathrm{i}}\right) ; \beta_{0}$ denotes the intercepts at a specific location $\left(\mu_{i}, v_{i}\right)$; and $\beta_{1}$ is the location-specific slope for $X_{i}, X_{i}$ denotes AQI, $\mathrm{PM}_{2.5}$, $\mathrm{PM}_{10}, \mathrm{SO}_{2}, \mathrm{CO}, \mathrm{NO}_{2}, \mathrm{PRE}, \mathrm{RH}, \mathrm{TEM}$, and WS, respectively. The location $\left(\mu_{i}, v_{i}\right)$ represents the central coordinates of city $i$, and $\varepsilon_{i}$ is the error term for sample $i$.

\section{Results and discussion}

\section{Descriptive statistical analysis}

Table 1 demonstrated the statistical results for daily COVID19 confirmed incidence (per 100, 000, 0), meteorological determinates, and air pollutants during the study period including before lockdown, lockdown, and after lockdown. The maximum mean daily confirmed rate (3.33) occurred during the lockdown period, followed by after lockdown (1.18), and before lockdown (0.73).
Before lockdown, the mean daily meteorological determinates including PRE, RH, TEM, and WS were $1.53 \mathrm{~mm}$, $8.00 \%, 7.82{ }^{\circ} \mathrm{C}$, and $1.86 \mathrm{~m} / \mathrm{s}$, respectively. The daily average concentrations of air pollutants concerning $\mathrm{AQI}, \mathrm{O}_{3}, \mathrm{CO}$, $\mathrm{NO}^{2}, \mathrm{PM}_{2.5}, \mathrm{PM}_{10}$, and $\mathrm{SO}_{2}$ were $78.11,46.67 \mu \mathrm{g} / \mathrm{m}^{3}, 9.35$ $\mu \mathrm{g} / \mathrm{m}^{3}, 34.91 \mu \mathrm{g} / \mathrm{m}^{3}, 61.34 \mu \mathrm{g} / \mathrm{m}^{3}, 69.27 \mu \mathrm{g} / \mathrm{m}^{3}$, and 14.69 $\mu \mathrm{g} / \mathrm{m}^{3}$, respectively.

During the lockdown period, the average daily meteorological determinates including PRE, RH, TEM, and WS were $2.26 \mathrm{~mm}, 7.36 \%, 5.33{ }^{\circ} \mathrm{C}$, and $2.15 \mathrm{~m} / \mathrm{s}$, respectively. The daily mean concentrations of air pollutants concerning AQI, $\mathrm{O}_{3}, \mathrm{CO}, \mathrm{NO}_{2}, \mathrm{PM}_{2.5}, \mathrm{PM}_{10}$, and $\mathrm{SO}_{2}$ were $58.02,52.85 \mu \mathrm{g} /$ $\mathrm{m}^{3}, 15.60 \mu \mathrm{g} / \mathrm{m}^{3}, 26.89 \mu \mathrm{g} / \mathrm{m}^{3}, 50.80 \mu \mathrm{g} / \mathrm{m}^{3}, 53.55 \mu \mathrm{g} / \mathrm{m}^{3}$, and $23.39 \mu \mathrm{g} / \mathrm{m}^{3}$, respectively.

After lockdown, the average daily meteorological determinates including PRE, RH, TEM, and WS were $2.40 \mathrm{~mm}$, $6.83 \%, 14.47^{\circ} \mathrm{C}$, and $2.39 \mathrm{~m} / \mathrm{s}$, respectively. The daily mean concentrations of air pollutants concerning $\mathrm{AQI}, \mathrm{O}_{3}, \mathrm{CO}$, $\mathrm{NO}_{2}, \mathrm{PM}_{2.5}, \mathrm{PM}_{10}$, and $\mathrm{SO}_{2}$ were $59.61,76.55 \mu \mathrm{g} / \mathrm{m}^{3}, 1.05$ $\mu \mathrm{g} / \mathrm{m}^{3}, 33.89 \mu \mathrm{g} / \mathrm{m}^{3}, 37.35 \mu \mathrm{g} / \mathrm{m}^{3}, 59.98 \mu \mathrm{g} / \mathrm{m}^{3}$, and $9.20 \mu \mathrm{g} /$ $\mathrm{m}^{3}$, respectively.

The distribution of COVID-19 confirmed cases exhibited significant spatial heterogeneity during the outbreak of the pandemic (Fig.2). The majority of positive incidences were accumulated in the east of China. Also, the most concentrated of COVID-19 confirmed incidences were distributed in the Hubei Province during the lockdown period. Meanwhile, the distribution of $\mathrm{PM}_{2.5}$ concentration in China also exhibited strong regional variation during the spread of the epidemic, that is, the concentrations in the southeast of China were higher than the northwest of China. Also, the $\mathrm{PM}_{2.5}$ concentrations in central, northeast, and northwest of China represented higher than the rest of the areas in China. Especially, the distribution of COVID-19 confirmed incidences was almost consistent with the $\mathrm{PM}_{2.5}$ concentrations in China. The possible reason for the similar distribution feature concerning COVID-19 confirmed incidences and $\mathrm{PM}_{2.5}$ concentrations was that a series of measures especially lockdown has been taken by the local government. The spreading of the pandemic to the rest of China was prevented due to the effective restrictions, whereas a published study confirmed that the COVID19 had been spreading in Italy for several weeks before the measures were taken by government authorities (Cereda et al. 2020). So, we inferred that a similar geographical distribution concerning COVID-19 incidence and air pollution did not occur coincidently but may present statistically significant.

\section{The relations between environmental as well as meteorological factors and the COVID-19 confirmed incidences on globally perspective}

The GWR model was implemented to identify the global relations between environmental and meteorological factors and 
Table 1 Descriptive statistics for daily COVID-19 confirmed incidence (per 100, 000, 0), meteorological determinates, and air pollutants across China during the study period

\begin{tabular}{|c|c|c|c|c|c|}
\hline $\begin{array}{l}\text { Study } \\
\text { period }\end{array}$ & Data & Mean & SD & Min & Max \\
\hline \multirow[t]{13}{*}{ Before lockdown } & Daily confirmed & 0.73 & 1.52 & 0.04 & 8.71 \\
\hline & rate (per $100,000,0)$ & & & & \\
\hline & PRE (mm) & 1.53 & 4.33 & 0.00 & 20.70 \\
\hline & $\mathrm{RH}(\%)$ & 8.00 & 1.33 & 3.80 & 10.00 \\
\hline & TEM $\left({ }^{\circ} \mathrm{C}\right)$ & 7.82 & 7.97 & -14.40 & 22.30 \\
\hline & WS $(\mathrm{m} / \mathrm{s})$ & 1.86 & 1.48 & 0.40 & 13.00 \\
\hline & AQI & 78.11 & 44.84 & 24.26 & 207.16 \\
\hline & $\mathrm{O}_{3}\left(\mu \mathrm{g} / \mathrm{m}^{3}\right)$ & 46.67 & 18.92 & 18.33 & 100.61 \\
\hline & $\mathrm{CO}\left(\mu \mathrm{g} / \mathrm{m}^{3}\right)$ & 9.35 & 19.76 & 0.32 & 89.49 \\
\hline & $\mathrm{NO}_{2}\left(\mu \mathrm{g} / \mathrm{m}^{3}\right)$ & 34.91 & 15.83 & 5.89 & 76.46 \\
\hline & $\mathrm{PM}_{2.5}\left(\mu \mathrm{g} / \mathrm{m}^{3}\right)$ & 61.34 & 33.86 & 9.00 & 160.47 \\
\hline & $\mathrm{PM}_{10}\left(\mu \mathrm{g} / \mathrm{m}^{3}\right)$ & 69.27 & 39.95 & 22.28 & 213.63 \\
\hline & $\mathrm{SO}_{2}\left(\mu \mathrm{g} / \mathrm{m}^{3}\right)$ & 14.69 & 14.42 & 2.38 & 54.97 \\
\hline \multirow[t]{13}{*}{ Lockdown } & Daily confirmed & 3.33 & 26.67 & 0.03 & 1520.37 \\
\hline & rate (per $100,000,0)$ & & & & \\
\hline & PRE (mm) & 2.26 & 6.69 & 0.00 & 80.00 \\
\hline & $\mathrm{RH}(\%)$ & 7.36 & 1.65 & 1.40 & 10.00 \\
\hline & TEM $\left({ }^{\circ} \mathrm{C}\right)$ & 5.33 & 8.51 & -24.5 & 22.7 \\
\hline & WS (m/s) & 2.15 & 1.31 & 0.20 & 13.60 \\
\hline & AQI & 58.02 & 39.51 & 10.92 & 390.17 \\
\hline & $\mathrm{O}_{3}\left(\mu \mathrm{g} / \mathrm{m}^{3}\right)$ & 52.85 & 18.98 & 4.79 & 123.34 \\
\hline & $\mathrm{CO}\left(\mu \mathrm{g} / \mathrm{m}^{3}\right)$ & 15.60 & 19.84 & 0.19 & 113.02 \\
\hline & $\mathrm{NO}_{2}\left(\mu \mathrm{g} / \mathrm{m}^{3}\right)$ & 26.89 & 18.21 & 1.96 & 147.91 \\
\hline & $\mathrm{PM}_{2.5}\left(\mu \mathrm{g} / \mathrm{m}^{3}\right)$ & 50.80 & 36.80 & 0.00 & 480.63 \\
\hline & $\mathrm{PM}_{10}\left(\mu \mathrm{g} / \mathrm{m}^{3}\right)$ & 53.55 & 36.12 & 0.00 & 455.67 \\
\hline & $\mathrm{SO}_{2}\left(\mu \mathrm{g} / \mathrm{m}^{3}\right)$ & 23.39 & 19.80 & 1.96 & 170.47 \\
\hline After & Daily confirmed rate (per $100,000,0$ ) & 1.18 & 2.36 & 0.04 & 7.46 \\
\hline \multirow[t]{11}{*}{ lockdown } & PRE (mm) & 2.40 & 6.92 & 0.00 & 41.40 \\
\hline & $\mathrm{RH}(\%)$ & 6.83 & 1.78 & 1.70 & 10.00 \\
\hline & TEM $\left({ }^{\circ} \mathrm{C}\right)$ & 14.47 & 5.02 & 5.7 & 27.8 \\
\hline & WS $(\mathrm{m} / \mathrm{s})$ & 2.39 & 1.02 & 0.40 & 6.70 \\
\hline & AQI & 59.61 & 36.92 & 16.96 & 280.21 \\
\hline & $\mathrm{O}_{3}\left(\mu \mathrm{g} / \mathrm{m}^{3}\right)$ & 76.55 & 21.91 & 25.12 & 154.67 \\
\hline & $\mathrm{CO}\left(\mu \mathrm{g} / \mathrm{m}^{3}\right)$ & 1.05 & 4.33 & 0.38 & 53.67 \\
\hline & $\mathrm{NO}_{2}\left(\mu \mathrm{g} / \mathrm{m}^{3}\right)$ & 33.89 & 15.84 & 8.12 & 96.96 \\
\hline & $\mathrm{PM}_{2.5}\left(\mu \mathrm{g} / \mathrm{m}^{3}\right)$ & 37.35 & 33.40 & 4.17 & 275.88 \\
\hline & $\mathrm{PM}_{10}\left(\mu \mathrm{g} / \mathrm{m}^{3}\right)$ & 59.98 & 42.50 & 10.33 & 330.71 \\
\hline & $\mathrm{SO}_{2}\left(\mu \mathrm{g} / \mathrm{m}^{3}\right)$ & 9.20 & 5.58 & 2.71 & 52.11 \\
\hline
\end{tabular}

the COVID-19 confirmed incidences during three different study periods across China. The degree of correlation was represented by a decision coefficient $\left(R^{2}\right)$ and the $R^{2}$ values for each independent variable varied significantly among the different study periods and lag group (Fig. 3). The correlation between environmental as well as meteorological factors and the number of COVID-19 confirmed incidences was the weakest $\left(\mathrm{R}^{2}<0.1\right)$ during the lockdown period for each lag group, and the lag effects of the independent variable on the number of COVID-19 confirmed incidences were not significant. On the contrary, the highest correlation was identified during the lockdown period. Furthermore, for most independent variables except $\mathrm{CO}, \mathrm{RH}$, and $\mathrm{SO}_{2}$, the lag effect on the number of COVID-19 confirmed incidences exhibited a heightening trend after the lockdown period, that is, the longer lag days, the higher $\mathrm{R}^{2}$. Additionally, the relation concerning 

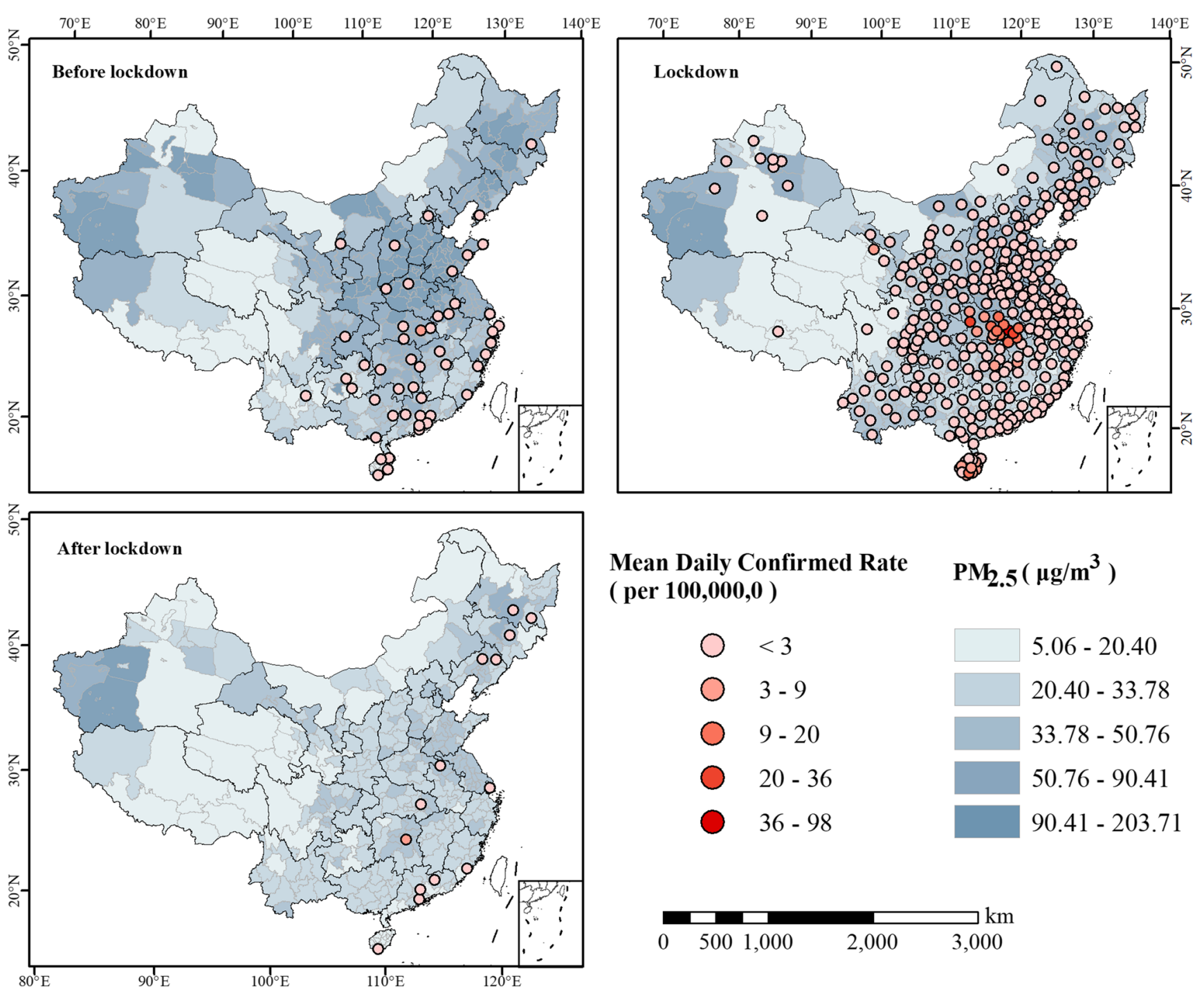

Fig. 2. The distribution map of the mean daily confirmed rate of COVID-19 and the $\mathrm{PM}_{2.5}$ concentrations across China during the study period.

independent variables and the number of COVID-19 confirmed incidences were moderate before lockdown period for each lag group, and the lag effect on the number of COVID-19 confirmed cases increasing in line with the lag days for parts independent variables including $\mathrm{CO}$ and $\mathrm{SO}_{2}$.

Besides, except for during the lockdown period, no matter which period and lag group environmental and meteorological factors are, the temperature exhibited a significant impact on COVID-19 confirmed incidences especially during after lockdown period, followed by $\mathrm{PM}_{2.5}$, WS, AQI, $\mathrm{O}_{3}, \mathrm{PRE}, \mathrm{NO}_{2}$, $\mathrm{PM}_{10}$ (Fig. 3, Table S1-S4).

Fig. 4 showed that the coefficient obtained from the GWR model for each air pollutant as well as meteorological factor varies based on different study period including before lockdown, lockdown period, after lockdown, and lag group in terms of lag 0, lag 7, lag 14 and lag 21 (Fig. 4, Table S1-S4).

\section{The effects of environmental and meteorological factors on COVID-19 confirmed incidences from the local perspective}

The effects of environmental and meteorological factors on COVID-19 confirmed incidences were detected by the GWR model during two different study periods at the lag 21 group in China. The lockdown period was not taken into account for the relations between possible determinants and COVID-19 confirmed incidences were relatively weak, and the probable reason was the specific measures were carried out such as keeping social distancing, wearing a mask, and shutting down some industries during the lockdown period. Also, the other lag group was excluded because we found that the relationship between affecting factors and COVID-19 confirmed incidences were relatively significant at lag 21 days group (Fig. 3). 
Fig. 3. The $\mathrm{R}^{2}$ of meteorological determinates and air pollutants for COVID-19 confirmed incidences based on the GWR model during three study periods with four lag groups. (Note: The $\mathrm{R}^{2}$ is significant at $\mathrm{p}<0.05$ )

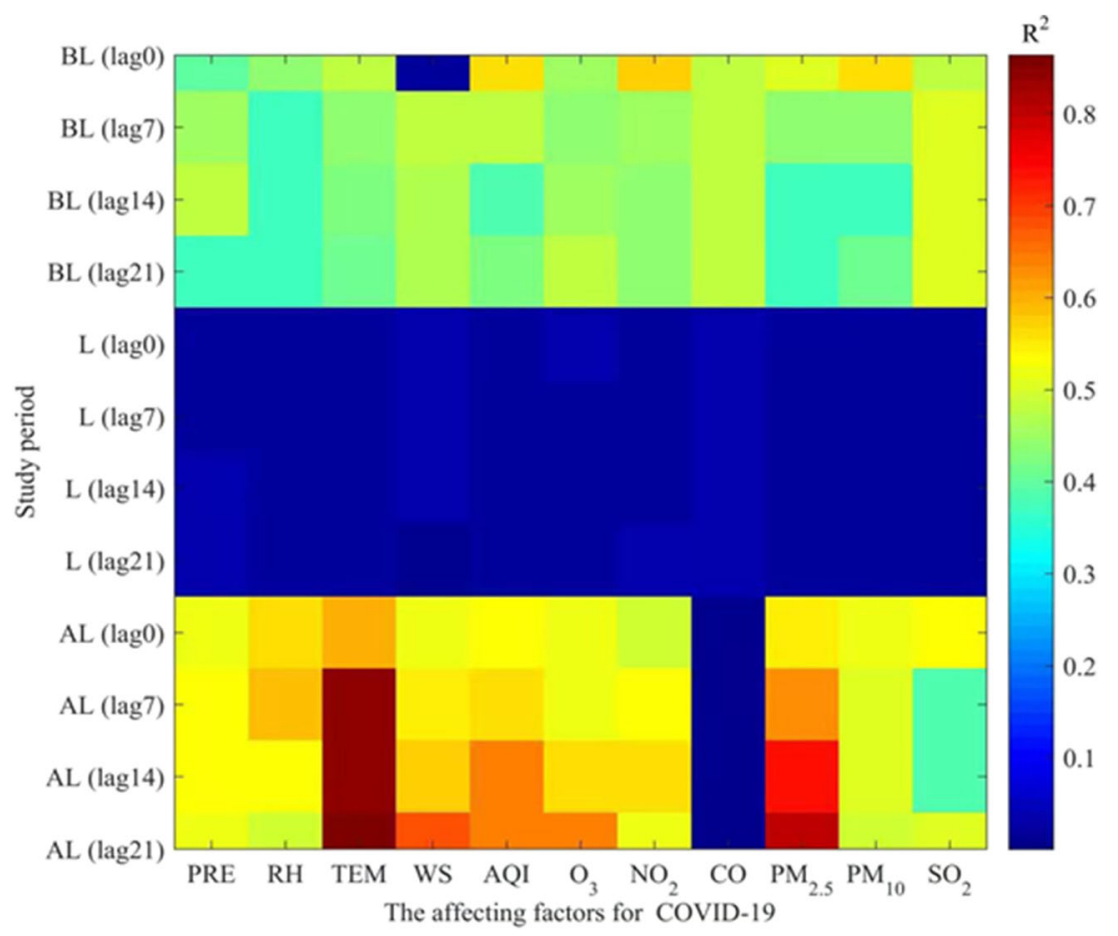

The influences of each environmental and meteorological factor on COVID-19 confirmed incidences present significantly spatial heterogeneity. Figures 5 and 6 demonstrated that a given factor influenced COVID-19 confirmed incidences according to location. The variously estimated coefficients demonstrated that there exist positive and negative variations in the influences of each environmental and meteorological determinant on COVID-19 confirmed incidences at P less than 0.05 significant level.

Clearly, for before lockdown with lag21 day group, WS, $\mathrm{O}_{3}$, and TEM represented a negative impact on COVID-19 confirmed incidences in most areas of China (blue and dark blue dots), and the higher degree of the negative effect is mainly distributed in central and east of China (Fig. 5(c) Fig.
Fig. 4. The coefficient of meteorological determinates and air pollutants for COVID-19 confirmed incidences based on the GWR model during three study periods and four lag groups. (Note: The coefficients are significant at $\mathrm{p}<0.05$ )

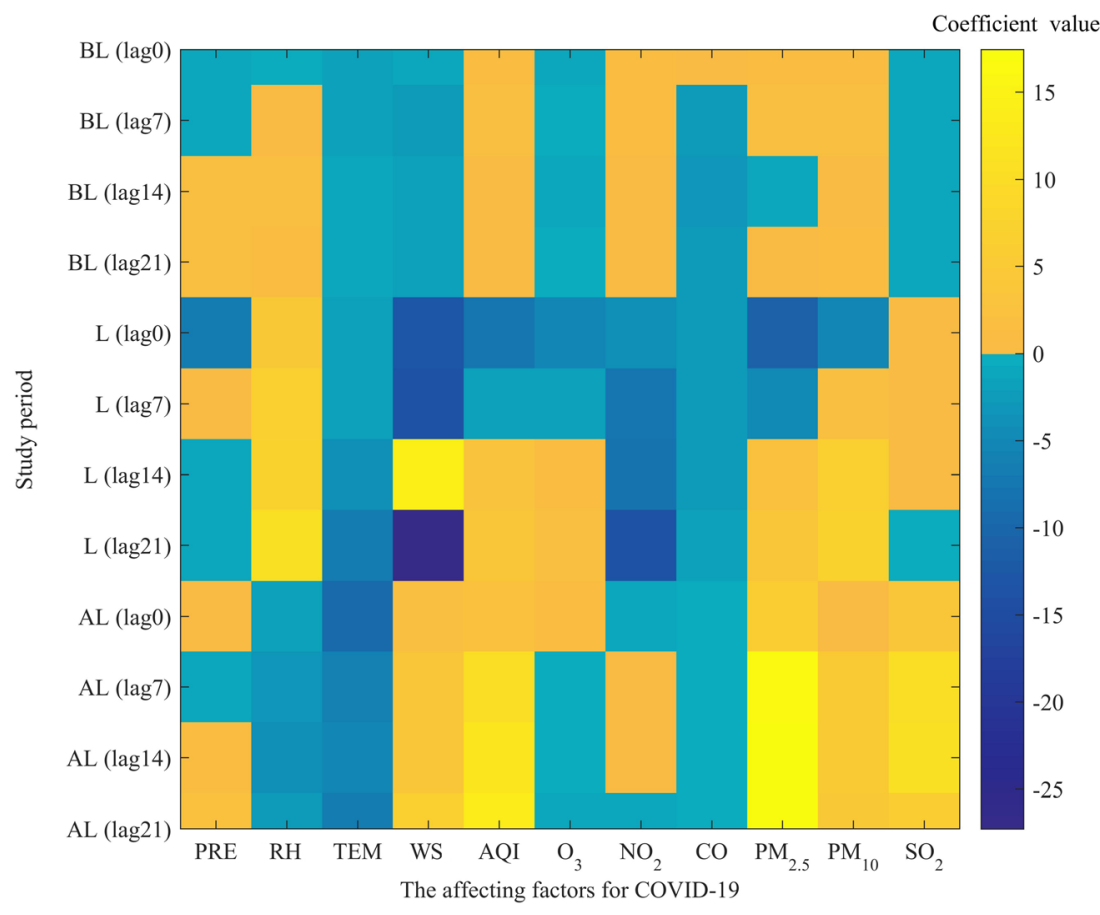



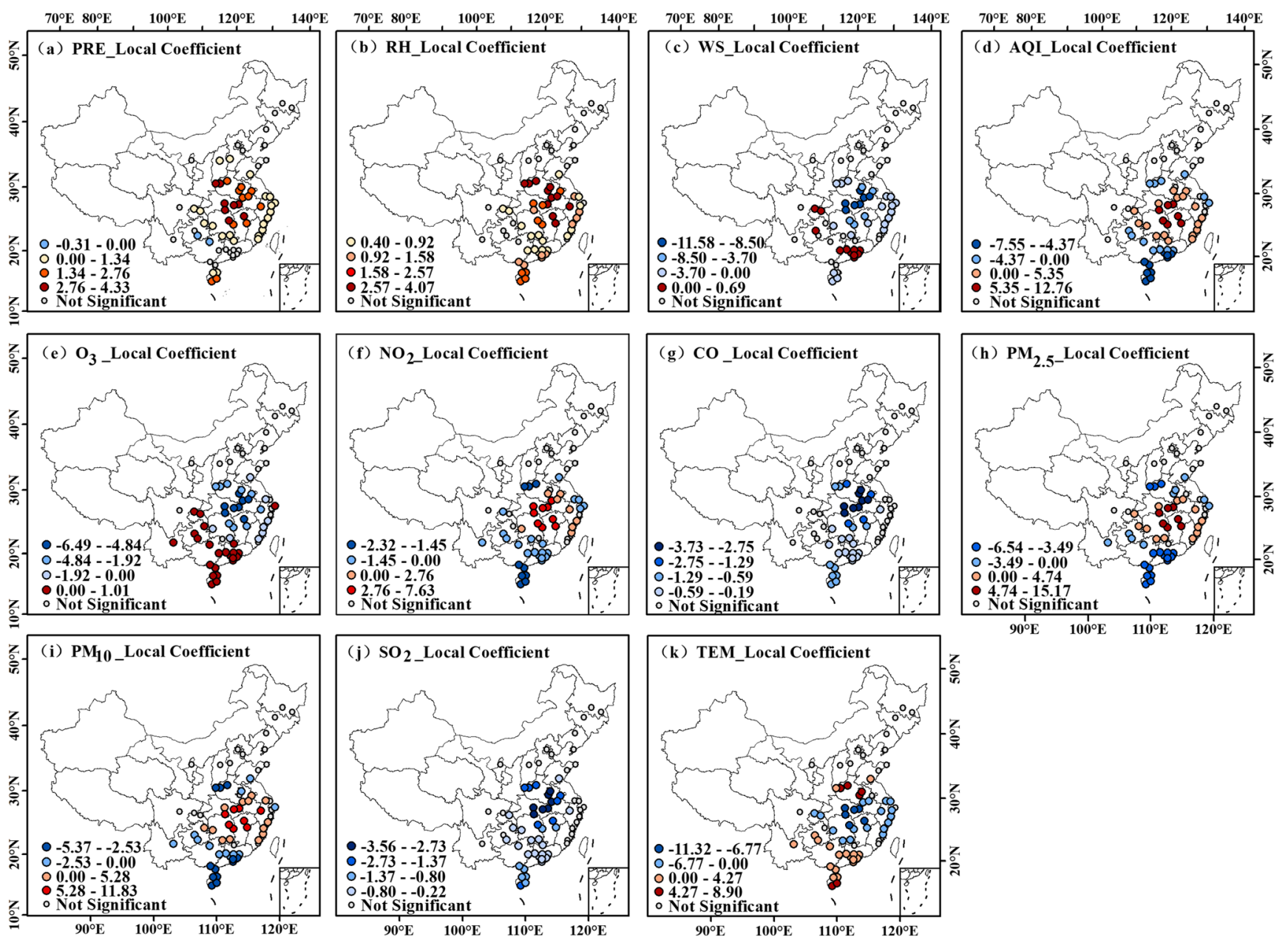

Fig. 5 The map for local coefficients of meteorological determinates and air pollutants is based on GWR before lockdown with the lag 21 days group

5 (e) Fig. 5(k)). Contrarily, relative humidity revealed a positive relationship with COVID-19 confirmed incidences across China (yellow, orange, and red dots) (Fig. 5(b)). Meanwhile, AQI, $\mathrm{PM}_{2.5}, \mathrm{PM}_{10}$, and $\mathrm{NO}_{2}$ showed a positive effect on COVID-19 confirmed incidences in most areas of China (yellow, orange, and red dots), and the higher degree of positive impact is mainly concentrated in central and east of China (Fig. 5(d) Fig. 5(h) Fig. 5(i) Fig. 5(f)).

After lockdown at the lag21 day group, $\mathrm{CO}$ presented a negative effect on COVID-19 confirmed incidences in the whole of China (blue and dark blue dots), and the higher degree of negative effect was mainly distributed in Guangdong province (Fig. 6(g)). However, precipitation, relative humidity, and temperature pose a positive impact on the number of COVID-19 confirmed incidences in the east and northeast of China (yellow, orange, and red dots) but exhibited a negative effect on COVID-19 confirmed incidences in the southeast of China (blue and dark blue dots) (Fig. 6(a) Fig. 6(b) Fig. 6(i)). Besides, $\mathrm{AQI}, \mathrm{SO}_{2}, \mathrm{PM}_{10}$, and $\mathrm{PM}_{2.5}$ represented a negative relationship with COVID-19 confirmed incidences in the northeast of China (blue and dark blue dots) but showed a positive effect on COVID-19 confirmed incidences in the southeast of China (yellow, orange, and red dots) (Fig. 6(d) Fig. 6(j) Fig. 6(i) Fig. 6(h)). So, if the effect of spatial and temporal heterogeneity on COVID-19 confirmed incidences was neglected and the impacts of all variables on COVID-19 confirmed incidences were only evaluated at the global perspective, there may be a large bias in the results.

\section{Discussion}

\section{The comparison between our findings and previous studies}

Given the published literature, air pollutants, as well as meteorological factors, exhibited an obvious impact on COVID-19 confirmed incidences. So, the comparison was conducted between the outcomes of the current study and published researches to reveal differences and similarities.

The current study found that AQI, $\mathrm{PM}_{2.5}$, and $\mathrm{PM}_{10}$ exhibited significantly positive effects on COVID-19 confirmed incidences during the most study period and at the majority 

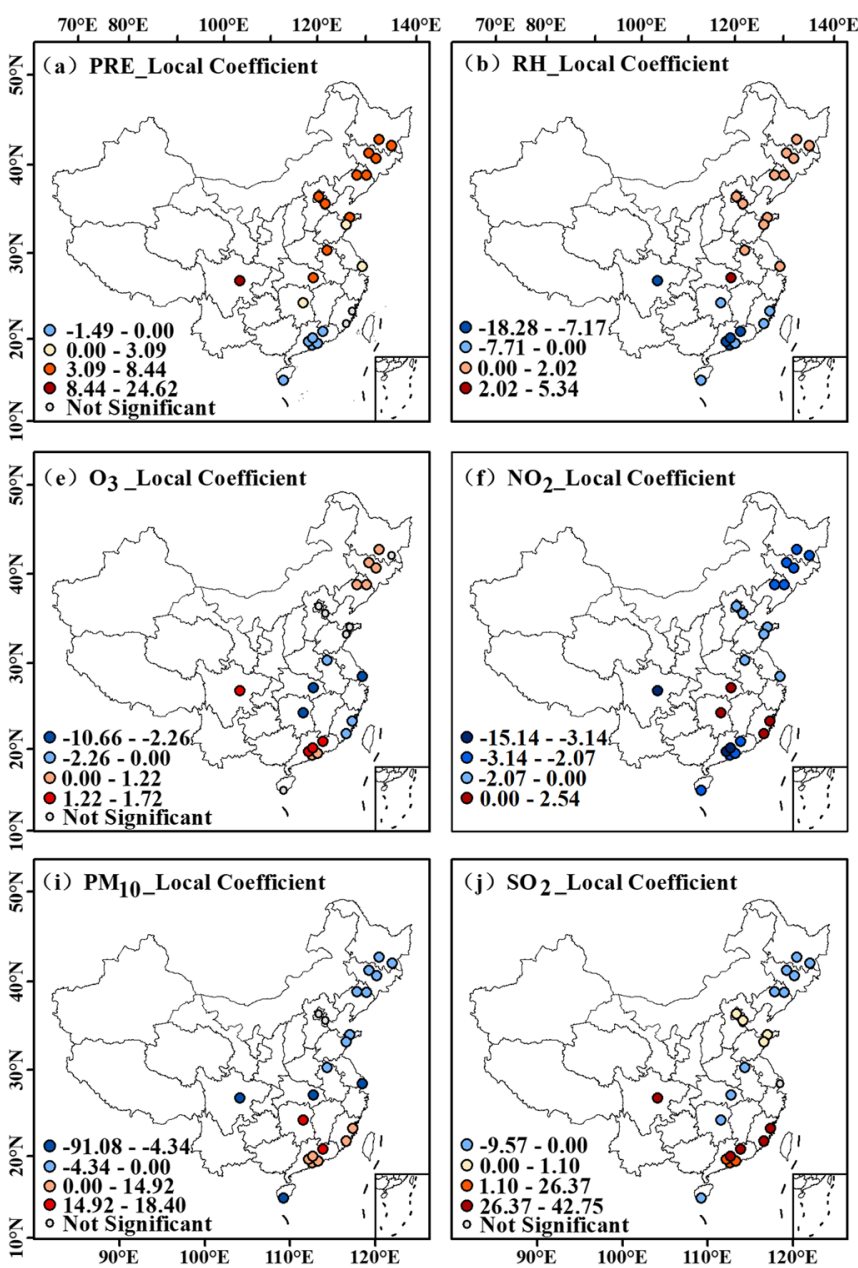

Fig. 6. The map for local coefficients of meteorological determinates and air pollutants is based on GWR after lockdown with the lag 21 days group. (Note: the other maps for local coefficients of meteorological

lag group (Fig. 3). These outcomes had also been proved by some scholars from different countries (Li et al. 2020b; Chen et al. 2020; Wu et al. 2020a; Yao et al. 2020; Fattorini and Regoli (2020); Zhu et al. 2020; Suhaimi et al. 2020; Fronza et al. 2020). For example, one finding demonstrated that AQI represented a significantly positive impact on the number of daily confirmed COVID-19 incidences in Hubei province. $\mathrm{Wu}$ et al. (2020a) evaluated the influence of $\mathrm{PM}_{2.5}$ on COVID-19 mortality and revealed that only a $1 \mu \mathrm{g} / \mathrm{m}^{3}$ rise in $\mathrm{PM}_{2.5}$ is linked with a $15 \%$ increase in COVID-19 mortality. Yao et al. (2020) qualitatively analyzed the mortality of COVID-19 and spatial correlation of $\mathrm{PM}_{10}$ and $\mathrm{PM}_{2.5}$ in China through multiple linear regression and pointed out that the mortality of COVID-19 and the concentration of $\mathrm{PM}_{10}$, as well as PM2.5, exhibited positive relations. Besides, Fattorini and Regoli (2020) assessed the relation between haze pollution and COVID-19 spread in Italy and showed continuous exposure to air pollutants in Northern Italy is the major cause of COVID-19 incidences. Furthermore, similar results were reported by related experts from China, the USA, Italy, and
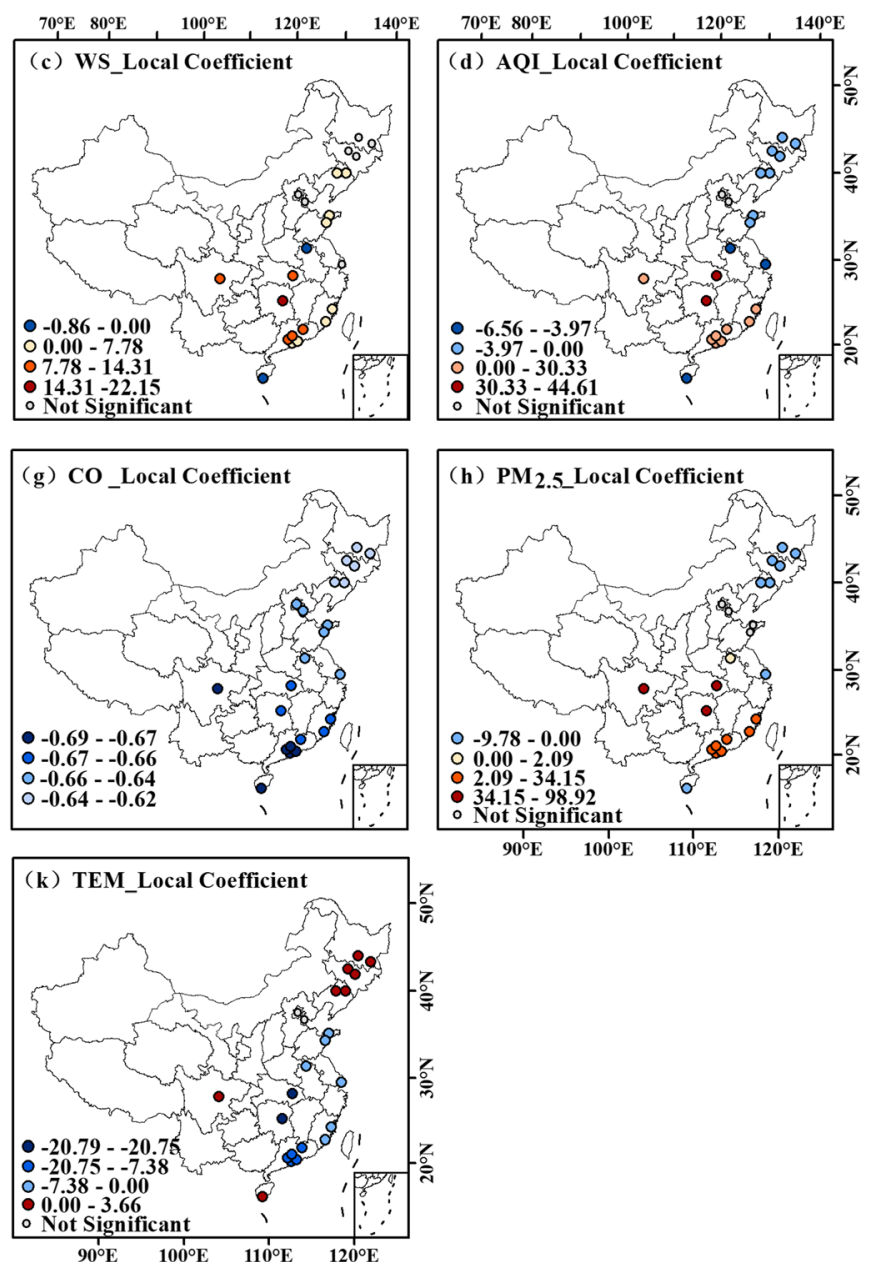

determinates and air pollutants based on GWR during the study period at the different lag group were presented in the supplement materials (Fig. S1-S6))

India ( Wang et al. 2020b; Piazzalunga-Expert 2020; Sharma et al. 2020). On the contrary, according to our findings, temperature showed negative impacts on COVID-19 confirmed incidences during all study period and at each lag group. $\mathrm{CO}$ demonstrated negative influences on COVID-19 confirmed incidences except for the before lockdown period with lag0 group, and $\mathrm{O}_{3}$ posed adverse efforts on COVID-19 confirmed incidences except for the lockdown period with lag14 and lag 21 groups and the after lockdown period with lag7 group (Fig. 4, Tables S1-S4). We reviewed the previous studies and found our results were consistent with some published researches. For example, the correlation of $\mathrm{O}_{3}$ with the number of COVID-19 infected incidences is negative (Fronza et al. 2020). Also, some previous researches found a negative relationship between average temperature and daily COVID-19 incidences (Suhaimi et al. 2020; Șahin 2020; Wang et al. 2020a; Wu et al. 2020b). Similarly, some studies inferred that the COVID-19 virus spread more smoothly in winter than in summer (Lipsitch 2020). Meanwhile, Fig. 5 and Fig. 6 obtained from the GWR model revealed that the effects of air 
pollutants, as well as meteorological factors on COVID-19, confirmed incidences existed obvious spatial heterogeneity feature, that is, the effects were not stable, but varied according to location. For example, the wind speed presented a positive effect on COVID-19 confirmed incidences during lockdown period with lag 14 group and after lockdown period with lag 0, lag 7, lag 14, lag 21 group (Fig.4, Table S1-S4), whereas the relations between COVID-19 confirmed incidences and wind speed were negative during another period which was consistent with a result from Iran (Ahmadi et al. 2020). Besides, the relative humidity posed an adverse impact on COVID-19 confirmed incidences during lockdown period with lag 14 group and after lockdown period with lag 0 , lag 7 , lag 14, and lag 21 group that is in line with some previous studies (Wu et al. 2020b; Li et al. 2020b). The probable reason is that the effectiveness of the immune system to COVID-19 viruses is limited in the circumstance with the lower humidity (Moriyama et al. 2020). However, the relations between COVID-19 confirmed incidences and relative humidity were positive during another period that is consistent with some previous researches (Suhaimi et al. 2020). Especially, although the positive relation of CO with COVID-19 confirmed incidences was detected before the lockdown period with the lag 0 group, $\mathrm{CO}$ showed a negative effect on COVID-19 confirmed incidences in most study period and majority lag group. This result was different from the published studies that $\mathrm{CO}$ generated a positive impact on COVID-19 confirmed incidences ( $\mathrm{Zhu}$ et al. 2020; Suhaimi et al. 2020; Li et al. 2020b). Additionally, $\mathrm{NO}_{2}$ revealed a positive effect on COVID-19 confirmed incidences during some study period and the lag group including BL (lag0), BL (lag7), BL (lag14), BL (lag21), AL (lag7), and AL (lag14) that is consistent with some previous researches (Zhu et al. 2020; Suhaimi et al. 2020; Chakraborty et al. 2020; Li et al. 2020b). $\mathrm{SO}_{2}$ exhibited both positive and negative effects on COVID-19 confirmed incidences. The virucidal property of $\mathrm{SO}_{2}$ may be a possible reason for the negative effect (Berendt et al. 1971).

\section{Why the correlation between air pollutants as well as meteorological factors and COVID-19 confirmed inci- dences are relatively weak during the lockdown period?}

We inferred that the air pollutants, as well as meteorological factors, did not represent higher effects on COVID-19 confirmed incidences during the lockdown period than another study period because the air pollutant concentration showed a decreasing trend during the lockdown period. Some previous studies from India (Mahato et al. 2020; Srivastava et al. 2020), China (Xu et al. 2020b; Bao and Zhang 2020; Wang et al. 2020c), Malaysia (Abdullah et al. 2020), and Kazakhstan (Kerimray et al. 2020) revealed the possible reason for air pollutants concentration decreasing is that some industries were shut down and the gas consumption was decreased during the lockdown period (Fig. 2, Table 1). Besides, the people were limited to move and urged to keep social distancing during the lockdown time. The possibility of exposure to air pollutants was lowered. So, the risk of COVID-19 spreading through particulate matter as well as meteorological factors was also reduced. Furthermore, the number of confirmed COVID-19 incidences was dramatically increased during the lockdown period because the main transmission route for COVID19 is person to person. Some positive measures were implemented by the Chinese government including only keeping basic factories and businesses open (such as food supplying, generating electricity, medical materials supplying especially mask and respirator producing) and closing gyms, public entertainment devices, hair salons, swimming pools, malls, and restaurant dining rooms. These tough measures effectively slowed the COVID-19 spreading across China (Fig. 2).

\section{The effect of a possible affecting factor on confirmed COVID-19 incidences vary based on the study period and lag group}

Figure 3 demonstrated that the effect of each air pollutant, as well as meteorological factor on confirmed COVID-19 incidences, varies based on different study periods including before lockdown, lockdown period, after lockdown, and lag group in terms of lag 0 , lag 7, lag 14, and lag 21 . The most significant effect of temperature $(0.531)$, wind speed (0.686), air quality (0.642), $\mathrm{O}_{3}(0.646), \mathrm{CO}$ (0.482), and $\mathrm{PM}_{2.5}$ (0.799) on confirmed COVID-19 incidences occurred during after lockdown period at lag 21 group (Fig.3, Table S1-S4). Besides, $\mathrm{PM}_{10}$ (0.558), $\mathrm{SO}_{2}$ (0.529), and $\mathrm{NO}_{2}(0.580)$ represented the largest impacts on confirmed COVID-19 incidences before lockdown, after lockdown, and before lockdown period with lag 0 group, respectively. The most significant impact of relative humidity $(0.591)$ and precipitation $(0.531)$ on confirmed COVID-19 incidences was identified during the after lockdown period at lag 7 group and lag 14 groups. The significant effect of the majority of air pollutants, as well as a meteorological factor on the confirmed COVID19 incidences, were mainly detected during the after lockdown period at the lag 21 group. Meanwhile, an incubation period of 1-14 days for COVID-19 was released by the Chinese National Health Commission. Some previous studies also pointed out that long-term exposure to air pollution increases the risk of mortality for COVID-19 (Wu et al. 2020a). So, we speculated that the longer people exposed to the environment, the larger the risk of people infected COVID-19 virus. 


\section{The limitation of the current study}

The COVID-19 was affected by many factors. In the present study, some possible factors in terms of the number of doctors, the condition of medical, the number of hospital beds, the gender and age of infected patients, the habitat, and living standard of patients were neglected due to the availability of related dataset. Furthermore, though the relation between air pollutants, as well as meteorological factors and confirmed COVID-19 incidences, was evaluated across China during the three periods at four lag group, this is a local, not a global attempt. The comparison between different regions and countries needs to be further addressed. The mechanism for the COVID-19 outbreak is complicated, and the interdisciplinary research especially medical mechanism is necessary. So, we plan to deep dive into the affecting factors for COVID-19 as follows. Firstly, some factors for COVID-19 such as the number of doctors and the living standard of patients will be supplemented to the GWR model. Secondly, the related methods used in the current study will be implemented in other regions for evaluating the feasibility and robustness if the related datasets can be made available. Thirdly, the study for the mechanism of the COVID-19 will be strengthened using interdisciplinary methods.

\section{Conclusion}

In the present study, the GWR model was conducted to explore the relations of possible meteorological determinates and air pollutants with daily COVID-19 confirmed incidences during the three-period at four lag group. Some findings were achieved. Firstly, AQI, $\mathrm{PM}_{2.5}$, and $\mathrm{PM}_{10}$ exhibited significantly positive effects on COVID-19 confirmed incidences during the most study period with the majority lag $\operatorname{group}(P<0.05)$. On the contrary, the temperature exhibited significantly negative impacts on COVID-19 confirmed incidences during the study period at each lag group $(P<0.05)$. Especially, CO showed a negative effect on COVID-19 confirmed incidences in most study period and majority lag group. Secondly, the effects of each possible environmental and meteorological determinant on COVID-19 confirmed incidences demonstrated spatial heterogeneity, that is, each given factor affected COVID-19 confirmed incidences in line with location. Thirdly, the tough measures taken by the Chinese government effectively prevented the COVID-19 virus transmission. Fourthly, the significant effect of the majority of air pollutants, as well as a meteorological factor on the confirmed COVID19 incidences, were mainly detected during the after lockdown period at the lag 21 group.

The outcome of this study confirmed that the lockdown was useful for controlling and preventing the spread of the pandemic. So, the serious regions with extensive confirmed cases of
COVID-19 should be urged to continue to keep lockdown. Moreover, the government should strengthen the measures for controlling the COVID-19 spreading in winter. Furthermore, the air pollution issue should be paid more attention to protecting human health. Specifically, the measures taken by the local governments should be differentiated because the impacts of each possible determinant on COVID-19 represented significantly spatial heterogeneity.

Abbreviations COVID-19, Corona Virus Disease 2019; SARS-CoV-2, severe acute respiratory syndrome coronavirus 2; MERS-CoV, middle east respiratory syndrome coronavirus; WHO, World Health Organization; GWR, Geographically Weighted Regression; SIMA, Society of Environmental Medicine; CNEMC, China National Environmental Monitoring Centre; GAM, Generalized Additive Model; $B L$, before lockdown; $L$, lockdown; $A L$, after lockdown; $P M$, particulate matter; $P M_{2.5}$, particles with diameters $\leq 2.5 \mu \mathrm{m} ; P M_{10}$, particles with diameters $\leq 10 \mu \mathrm{m} ; \mathrm{CO}$, carbon monoxide; $\mathrm{NO}_{2}$, nitrogen dioxide; $\mathrm{O}_{3}$, ozone; $\mathrm{SO}_{2}$, sulfur dioxide; $A Q I$, air quality index; TEM, temperature; $R H$, relative humidity; $P R E$, precipitation; $W S$, wind speed

Supplementary Information The online version contains supplementary material available at https://doi.org/10.1007/s11356-021-12934-6.

Acknowledgments We are deeply grateful to the School of Geography and Information Engineer at China University of Geosciences (Wuhan) for sharing the COVID-19 infected incidences data. Thank Master candidate Haojie $\mathrm{Wu}$ for collecting and preprocessing data.

Authors' contributions Lin Pei and Bin Guo were responsible for and writing the manuscript. Xiaoxia Wang was responsible for running data analysis. Hongjun Guo was responsible for data translation. Yan Yu was responsible for validation and supervision.

Funding This research was supported by the Fund Project of Shaanxi Key Laboratory of Land Consolidation (grant: 2019-JC11).

Data availability Not applicable

\section{Declarations}

Ethical approval The authors declare that all data used in the present study were approved.

Consent to participate Not applicable

Consent to publish Not applicable

Competing interests The authors declare that they have no competing interests.

\section{References}

Abdullah S, Mansor AA, Napi NNLM, Mansor WNW, Ahmed AN, Ismail M, Ramly ZTA (2020) Air quality status during 2020 Malaysia Movement Control Order (MCO) due to 2019 novel 
coronavirus (2019-nCoV) pandemic. Sci Total Environ 729: 139022. https://doi.org/10.1016/j.scitotenv.2020.139022

Adhikari A, Yin J (2020) Short-Term Effects of Ambient Ozone, PM2.5, and Meteorological Factors on COVID-19 Confirmed Incidences and Deaths in Queens, New York. Int J Environ Res Public Health 17(11):4047. https://doi.org/10.3390/ijerph17114047

Ahmadi M, Sharifi A, Dorosti S, Ghoushchi SJ, Ghanbari N (2020) Investigation of effective climatology parameters on COVID-19 outbreak in Iran. Sci Total Environ 729:138705. https://doi.org/10. 1016/j.scitotenv.2020.138705

Bao R, Zhang A (2020) Does lockdown reduce air pollution? Evidence from 44 cities in northern China. Sci Total Environ 731:139052. https://doi.org/10.1016/j.scitotenv.2020.139052

Berendt RF, Dorsey EL, Hearn HJ (1971) Virucidal properties of light and SO2 II. Effect of a low gas concentration on aerosolized virus. Proc Soc Exp Biol Med 138:1005-1008. https://doi.org/10.3181/ 00379727-138-36038

Bloom-Feshbach K, Alonso WJ, Charu V, Tamerius J, Simonsen L, Miller MA, Viboud C (2013) Latitudinal variations in seasonal activity of influenza and respiratory syncytial virus (RSV): a global comparative review. PLoS One 8(2):e54445. https://doi.org/10. 1371/journal.pone.0054445

Cereda, D., Tirani, M., Rovida, F., Demicheli, V., Ajelli, M., Poletti, P., Trentin, F., Guzzetta, G., Marziano, V., Barone, A., Magoni, M., Deandrea, S., Diurno, G., Lombardo, M., Faccini, M., Pan, A., Bruno, R., Pariani, E., Grasselli, G., Piatti, A., Gramegna, M., Baldanti, F., Melegaro, A., Merler, S., 2020. The Early Phase of the COVID-19 Outbreak in Lombardy, Italy. (pre-print). https:// arxiv.org/ftp/arxiv/papers/2003/2003.09320.pdf.

Chakraborty P, Jayachandran S, Padalkar P, Sitlhou L, Chakraborty S, Kar R, Bhaumik S, Srivastava M (2020) Exposure to nitrogen dioxide (NO2) from vehicular emission could increase the COVID-19 pandemic fatality in India: a perspective. B Environ Contam Tox 105(2):198-204. https://doi.org/10.1007/s00128-020-02937-3

Chen QX, Huang CL, Yuan Y, Tan HP (2020) Influence of COVID-19 Event on Air Quality and their Association in Mainland China. Aerosol Air Qual Res 20(7):1541-1551. https://doi.org/10.4209/ aaqr.2020.05.0224

Cui Y, Zhang Z-F, Froines J, Zhao J, Wang H, Yu S-Z, Detels R (2003) Air pollution and case fatality of SARS in the People's Republic of China: an ecologic study. Environ Health 2(1):1-5. https://doi.org/ 10.1186/1476-069X-2-15

Duan Y, Liao Y, Li H, Yan S, Zhao Z, Yu S, Fu Y, Wang Z, Yin P, Cheng $J$ (2019) Effect of changes in season and temperature on cardiovascular mortality associated with nitrogen dioxide air pollution in Shenzhen. China Sci Total Environ 697:134051. https://doi.org/10. 1016/j.scitotenv.2019.134051

Fattorini D, Regoli F (2020) Role of the chronic air pollution levels in the covid-19 outbreak risk in Italy. Environ Pollut 264:114732. https:// doi.org/10.1016/j.envpol.2020.114732

Fotheringham AS, Brunsdon C, Charlton M (2002) Geographically weighted regression: the analysis of spatially varying relationships. John Wiley \& Sons

Fronza R, Lusic M, Schmidt M, Lucic B (2020) Spatial-Temporal Variations in Atmospheric Factors Contribute to SARS-CoV-2 Outbreak. Viruses. 12(6):588. https://doi.org/10.3390/v12060588

Gardner EG, Kelton D, Poljak Z, Van Kerkhove M, von Dobschuetz S, Greer AL (2019) A case-crossover analysis of the impact of weather on primary cases of Middle East respiratory syndrome. BMC Infect Dis 19(1):1-10. https://doi.org/10.1186/s12879-019-3729-5

Guo B, Wang X, Zhang D, Pei L, Zhang D, Wang X (2020) A Land Use Regression Application into Simulating Spatial Distribution Characteristics of Particulate Matter (PM2.5) Concentration in City of Xi' an, China. Pol J Environ Stud 29(6):4065-4076. https:// doi.org/10.15244/pjoes/118426
Guo B, Wang X, Pei L, Su Y, Zhang D, Wang Y (2021a) Identifying the spatiotemporal dynamic of PM2.5 concentrations at multiple scales using geographically and temporally weighted regression model across China during 2015-2018. Sci Total Environ 751:141765. https://doi.org/10.1016/j.scitotenv.2020.141765

Guo B, Wang Y, Pei L, Yu Y, Liu F, Zhang D, Wang X, Su Y, Zhang D, Zhang B, Guo H (2021b) Determining the effects of socioeconomic and environmental determinants on chronic obstructive pulmonary disease (COPD) mortality using geographically and temporally weighted regression model across Xi'an during 2014-2016. Sci Total Environ 756:143869. https://doi.org/10.1016/j.scitotenv. 2020.143869

Hastie TJ (2017) Generalized Additive Models, Statistical Models in S. Routledge, pp 249-307

Huang C, Wang Y, Li X, Ren L, Zhao J, Hu Y, Zhang L, Fan G, Xu J, Gu $X$ (2020) Clinical features of patients infected with 2019 novel coronavirus in Wuhan, China. Lancet 395:497-506. https://doi.org/10. 1016/S0140-6736(20)30183-5

Italian National Institute of Health (ISS) (2020) Coronavirus Surveillance Bulletin March 19/20. Available online: https://www.epicentro.iss. it/coronavirus/bollettino/Bollettino-sorveglianza-integrata-COVID19_16-aprile-2020.pdf.

Italian Society of Environmental Medicine (SIMA) (2020) Position Paper Particulate Matter and COVID-19. Available online: http://www. simaonlus.it/wpsima/wp-content/uploads/2020/03/COVID_19_ position-paper_ENG.pdf.

Kerimray A, Baimatova N, Ibragimova OP, Bukenov B, Kenessov B, Plotitsyn P, Karaca F (2020) Assessing air quality changes in large cities during COVID-19 lockdowns: The impacts of traffic-free urban conditions in Almaty. Kazakhstan Sci Total Environ 730: 139179. https://doi.org/10.1016/j.scitotenv.2020.139179

Li Y, Wang X-L, Zheng X (2018) Impact of weather factors on influenza hospitalization across different age groups in subtropical Hong Kong. Int J Biometeorol 62:1615-1624. https://doi.org/10.1007/ s00484-018-1561-z

Li H, Liu SM, Yu XH, Tang SL, Tang CK (2020a) Coronavirus disease 2019 (COVID-19): current status and future perspectives. Int J Antimicrob Agents 55(5):105951. https://doi.org/10.1016/j. ijantimicag.2020.105951

Li H, Xu XL, Dai DW, Huang ZY, Ma Z, Guan YJ (2020b) Air Pollution and temperature are associated with increased COVID-19 incidence: a time series study. Int J Infect Dis 97:278-282. https://doi.org/10. 1016/j.ijid.2020.05.076

Lin K, Yee-Tak Fong D, Zhu B, Karlberg J (2006) Environmental factors on the SARS epidemic: air temperature, passage of time and multiplicative effect of hospital infection. Epidemiol Infect 134:223-230. https://doi.org/10.1017/S0950268805005054

Lin H, Tao J, Kan H, Qian Z, Chen A, Du Y, Liu T, Zhang Y, Qi Y, Ye J (2018) Ambient particulate matter air pollution associated with acute respiratory distress syndrome in Guangzhou. China J Expo Sci Environ Epidemiol 28:392-399. https://doi.org/10.1038/s41370018-0034-0

Lipsitch M (2020) Seasonalityof SARS-CoV-2: will COVID-19 goawayon its owninwarmer weather? 2020 Available from: https:// ccdd.hsph.harvard.edu/will-covid-19- go-away-on-its-own-inwarmer-weather/.

Liu K, Hou X, Ren Z, Lowe R, Wang Y, Li R, Liu X, Sun J, Lu L, Song X (2020) Climate factors and the East Asian summer monsoon may drive large outbreaks of dengue in China. Environ Res 183:109190. https://doi.org/10.1016/j.envres.2020.109190

Lowen AC, Mubareka S, Steel J, Palese P (2007) Influenza virus transmission is dependent on relative humidity and temperature. PLoS Pathog 3(10):0030151. https://doi.org/10.1371/journal.ppat. 0030151

Lu R, Zhao X, Li J, Niu P, Yang B, Wu H, Wang W, Song H, Huang B, Zhu N, Bi Y, Ma X, Zhan F, Wang L, Hu T, Zhou H, Hu Z, Zhou W, 
Zhao L, Chen J, Meng Y, Wang J, Lin Y, Yuan J, Xie Z, Ma J, Liu WJ, Wang D, Xu W, Holmes EC, Gao GF, Wu G, Chen W, Shi W, Tan W (2020) Genomic characterisation and epidemiology of 2019 novel coronavirus: implications for virus origins and receptor binding. Lancet. 395:565-574. https://doi.org/10.1016/S0140-6736(20) 30251-8

Mahato S, Pal S, Ghosh KG (2020) Effect of lockdown amid COVID-19 pandemic on air quality of the megacity Delhi, India. Sci Total Environ 730:139086. https://doi.org/10.1016/j.scitotenv.2020. 139086

Moriyama M, Hugentobler W, Iwasaki A (2020) Seasonality of respiratory viral infections. Annu Rev Virol 7:83-101. https://doi.org/10. 1146/annurev-virology-012420022445

Myung W, Lee H, Kim H (2019) Short-term air pollution exposure and emergency department visits for amyotrophic lateral sclerosis: A time-stratified case-crossover analysis. Environ Int 123:467-475. https://doi.org/10.1016/j.envint.2018.12.042

NHC (National Health Commission, China) (2020) Update on new coronavirus pneumonia epidemic as of $24: 00$ on February 15 . http:// $\mathrm{w} w \mathrm{w} \cdot \mathrm{n} \mathrm{h} \mathrm{c} \cdot \mathrm{gov} \cdot \mathrm{c} \mathrm{n} / \mathrm{x} \mathrm{c} \mathrm{s} / \mathrm{y} \mathrm{q} \mathrm{t} \mathrm{b/202002//}$ 4a1b1ec6c03548099de1c3aa935d04fd.shtml (accessed on 20 February 2020).

Piazzalunga-Expert A (2020) Evaluation of the Potential Relationship between Particulate Matter (PM) Pollution and COVID-19 Infection Spread in Italy. Mimeo

Șahin M (2020) Impact of weather on COVID-19 pandemic in turkey. Sci Total Environ 728:138810. https://doi.org/10.1016/j.scitotenv.2020. 138810

Setti L, Passarini F, De Gennaro G, Barbieri P, Perrone MG, Piazzalunga A, Borelli M, Palmisani J, Di Gilio A, Piscitelli P et al (2020) Is There a Plausible Role for Particulate Matter in the Spreading of COVID-19in Northern Italy? BMJ Rapid Responses Available online: https://www.bmj.com/content/368/bmj.m1103/rapidresponses

Sharma S, Zhang M, Gao J, Zhang H, Kota SH (2020) Effect of restricted emissions during COVID-19 on air quality in India. Sci Total Environ 728:138878. https://doi.org/10.1016/j.scitotenv.2020. 138878

Sohrabi C, Alsafi Z, O’Neill M, Khan M, Kerwan A, Al-Jabir A, Iosifidis C, Agha R (2020) World Health Organization declares global emergency: a review of the 2019 novel coronavirus (COVID-19). Int J Surg 76:71-76. https://doi.org/10.1016/j.ijsu.2020.02.034

Srivastava S, Kumar A, Bauddh K, Gautam AS, Kumar S (2020) 21-Day Lockdown in India Dramatically Reduced Air Pollution Indices in Lucknow and New Delhi. India B Environ Contam Tox 150(1):917. https://doi.org/10.1007/s00128-020-02895-w

Suhaimi NF, Jalaludin J, Latif MT (2020) Demystifying a possible relationship between COVID-19, air quality and meteorological factors: evidence from Kuala Lumpur, Malaysia. Aerosol Air Qual. Res. 20(7):1520-1529. https://doi.org/10.4209/aaqr.2020.05.0218

Wang J, Tang K, Feng K, Lv W (2020a) High temperature and high humidity reduce the transmission of COVID-19. SSRN Electron J. https://doi.org/10.2139/ssrn.3551767

Wang P, Chen K, Zhu S, Wang P, Zhang H (2020b) Severe air pollution events not avoided by reduced anthropogenic activities during COVID-19 outbreak. Resour Conserv Recycl 158:104814. https:// doi.org/10.1016/j.resconrec.2020.104814

Wang Y, Yuan Y, Wang Q, Liu C, Zhi Q, Cao J (2020c) Changes in air quality related to the control of coronavirus in China: Implications for traffic and industrial emissions. Sci Total Environ 731:139133. https://doi.org/10.1016/j.scitotenv.2020.139133

WHO (World Health Organization) (2020a) Statement on the second meeting of the international health regulations (2005) emergency committee regarding the outbreak of novel coronavirus (2019nCoV). https://www.who.int/news-room/detail/30-01- 2020statement-on-the-second-meeting-of-the-international-healthregulations-(2005)-emergency-committee-regarding-the-outbreakof-novel-coronavirus-(2019-ncov).

WHO (World Health Organization) (2020b) Coronavirus disease 2019 (COVID-19) situation report -26. https://www.who.int/docs/defaultsource/coronaviruse/situationreports/20200215-sitrep-26-covid-19. pdf?sfvrsn=a4cc6787 2.

Wu X, Nethery RC, Sabath BM, Braun D, Dominici F (2020a) Exposure to air pollution and COVID-19 mortality in the United States. medRxiv. https://doi.org/10.1101/2020.04.05.20054502

Wu Y, Jing W, Liu J, Ma Q, Yuan J, Wang Y, Du M, Liu M (2020b) Effects of temperature and humidity on the daily new incidences and new deaths of COVID-19 in 166 countries. Sci Total Environ 729: 139051. https://doi.org/10.1016/j.scitotenv.2020.139051

Xie J, Teng J, Fan Y, Xie R, Shen A (2019) The short-term effects of air pollutants on hospitalizations for respiratory disease in Hefei. China Int J Biometeorol 63(3):315-326. https://doi.org/10.1007/s00484018-01665-y

Xu H, Yan C, Fu Q, Xiao K, Yu Y, Han D, Wang W, Cheng J (2020a) Possible environmental effects on the spread of COVID-19 in China. Sci Total Environ 731:139211. https://doi.org/10.1016/j. scitotenv.2020.139211

Xu K, Cui K, Young LH, Hsieh YK, Wang YF, Zhang J, Wan S (2020b) Impact of the COVID-19 event on air quality in Central China. Aerosol Air Qual. Res. 20(5):915-929. https://doi.org/10.1016/j. scitotenv.2020.139211

Yang Z, Hao J, Huang S, Yang W, Zhu Z, Tian L, Lu Y, Xiang H, Liu S (2020) Acute effects of air pollution on the incidence of hand, foot, and mouth disease in Wuhan. China Atmos Environ 225:117358. https://doi.org/10.1016/j.atmosenv.2020.117358

Yao Y, Pan J, Wang W, Liu Z, Kan H, Meng X, Wang W (2020) Spatial Correlation of Particulate Matter Pollution and Death Rate of COVID-19. medRxiv. https://doi.org/10.1101/2020.04.07. 20052142

Yu ITS, Li Y, Wong TW, Tam W, Chan AT, Lee JHW, Leung DYC, Ho $\mathrm{T}$ (2004) Evidence of airborne transmission of the severe acute respiratory syndrome virus. N Engl J Med 350:1731-1739. https://doi. org/10.1056/NEJMoa032867

Zhou D, Zhang P, Bao C, Zhang Y, Zhu N (2020) Emerging understanding of etiology and epidemiology of the novel coronavirus (COVID19) infection in Wuhan, China (preprint). Life Sci. https://doi.org/ 10.20944/preprints202002.0283.v1

Zhu YJ, Xie JG, Huang FM, Cao LQ (2020) Association between shortterm exposure to air pollution and COVID-19 infection: Evidence from China. 727:138704. https://doi.org/10.1016/j.scitotenv.2020. 138704

Zumla A, Hui DS (2014) Infection control and MERS-CoV in health-care workers. Lancet 383:1869-1871. https://doi.org/10.1016/S01406736(14)60852-7

Publisher's note Springer Nature remains neutral with regard to jurisdictional claims in published maps and institutional affiliations. 